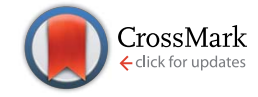

Cite this: J. Mater. Chem. A, 2015, 3, 18684

Received 25th June 2015 Accepted 31st July 2015

DOI: 10.1039/c5ta04681e

www.rsc.org/MaterialsA

\section{D Si/C particulate nanocomposites internally wired with graphene networks for high energy and stable batteries $\uparrow$}

\author{
Jaegyeong Kim, ${ }^{\text {a }}$ Changil Oh, ${ }^{a}$ Changju Chae, ${ }^{\text {ab }}$ Dae-Hoon Yeom, ${ }^{a}$ Jaeho $C h o i,{ }^{a}$ \\ Nahyeon Kim, ${ }^{a}$ Eun-Suok $\mathrm{Oh}^{c}$ and Jung Kyoo Lee*a
}

\begin{abstract}
It is challenging to design silicon anodes exhibiting stable cycling behavior, high volumetric and specific capacity, and low volume expansion for Li-based batteries. Herein, we designed Si/C-IWGN composites (Si/C composites internally wired with graphene networks). For this purpose, we used simple aqueous sol-gel systems consisting of varying amounts of silicon nanoparticles, resorcinol-formaldehyde, and graphene oxide. We found that a small amount of graphene (1-10 wt\%) in Si/C-IWGNs efficiently stabilized their cycling behavior. The enhanced cycling stability of Si/C-IWGNs could be ascribed to the following facts: (1) ideally dispersed graphene networks were formed in the composites, (2) these graphene networks also created enough void spaces for silicon to expand and contract with the electrode thickness increase comparable to that of graphite. Furthermore, properly designed Si/CIWGNs exhibited a high volumetric capacity of $\sim 141 \%$ greater than that of commercial graphite. Finally, a hybrid sample, Si-Gr, consisting of a high capacity Si/C-IWGN and graphite was prepared to demonstrate a hybrid strategy for a reliable and cost-effective anode with a capacity level required for high-energy Li-ion cells. The Si-Gr hybrid exhibited not only high capacity $\left(800-900 \mathrm{~mA} \mathrm{~h} \mathrm{~g}^{-1}\right.$ at $100 \mathrm{~mA} \mathrm{~g}^{-1}$ ) but also a high electrode volumetric capacity of $161 \%$ greater than that of graphite.
\end{abstract}

\section{Introduction}

Energy storage devices with high energy density are in great demand as they have widespread industrial applications. ${ }^{\mathbf{1 - 4}}$ Silicon is an attractive anode material not only for boosting the energy density of current Li-ion batteries but for the replacement of Li metal anodes in the newly emerging battery systems such as $\mathrm{Li}$-air and Li-S. This is because silicon has the highest lithium storage capacity among known elements, its capacity is closest to that of metallic lithium, and it has low voltage for charging..$^{5-13}$

However, it is quite challenging to devise a non-conducting silicon anode having stable cycling behavior at a practical level of electrode loading. In this silicon anode, electrode pulverization is caused by huge volume expansions $(\sim 300 \%))^{6,7}$ Moreover, the instability of the solid electrolyte interface (SEI) layer leads to poor coulombic efficiency repeatedly triggered by lithium alloying and de-alloying reactions. ${ }^{\mathbf{5 1 4 - 1 8}}$ Apart from the

${ }^{a}$ Department of Chemical Engineering, Dong-A University, Busan 604-714, Republic of Korea. E-mail: jklee88@dau.ac.kr; Fax:+82-51-200-7728; Tel: +82-51-200-7718

${ }^{b}$ Division of Advanced Materials, Korea Research Institute of Chemical Technology (KRICT), Daejeon 305-600, Republic of Korea

${ }^{c}$ School of Chemical Engineering \& Bioengineering, University of Ulsan, Ulsan 680-749, Republic of Korea

$\dagger$ Electronic supplementary information (ESI) available. See DOI: $10.1039 / \mathrm{c} 5 \mathrm{ta} 04681 \mathrm{e}$ life cycle issue, volume expansion of the electrode is one of the critical factors considered while designing commercial batteries to avoid cell failure. Nevertheless, it is quite challenging to design high capacity silicon-based composites, whose volume expansion level is more or less similar to that of the latest graphitic carbon anode. In addition, the design and synthetic process should be scalable with low-cost materials for siliconbased composites to become an alternative to graphitic carbon.

Recently, researchers have made remarkable progress in addressing the above issues associated with silicon. They have devised strategic material designs, which are effective in accommodating mechanical stresses in such a manner that the electrical integrity of the electrode is well maintained to deliver hundreds of stable cycles. ${ }^{\mathbf{1 6 , 1 7 , 1 9 - 2 7}}$ For mitigating the volume expansion problems, Si-based composites have been designed by two representative synthetic approaches. In the first approach, researchers have introduced an empty space of nanoscale between silicon and the conducting carbon matrix ${ }^{\mathbf{1 6}, \mathbf{1 9 - 2 2}}$ using sacrificial templates. The second approach involves the use of porous silicon structures..$^{23,24,26,28,29}$ Although these pioneering approaches are highly inspiring, they are also associated with different issues: the reduced electrode packing density leads to low volumetric energy density in the battery. Moreover, these approaches involve expensive processes, such as chemical vapor deposition of silicon or carbon, which cannot be transformed into commercially viable strategies. Furthermore, these 
complicated multi-step approaches involve the use of toxic chemicals for generating porous structures in either silicon or carbon matrix, thereby limiting their commercial use.

To tackle the above issues associated with silicon, graphene, which is a single-atom-thick layer of $\mathrm{sp}^{2}$ hybridized carbon in a two-dimensional (2D) format, has been effectively used as an attractive supporting material in devising high-storage capacity composites of silicon. ${ }^{\mathbf{3 0}-38}$ Graphene has many appealing properties such as excellent electrical conductivity, superior mechanical and chemical properties, and extremely high aspect ratio. ${ }^{39-44}$ Many other examples of advanced graphene-based composites have also been reported in the literature. For example, a small amount of graphene sheets is extremely effective as conductive fillers in polystyrene-graphene composites, because they have the lowest percolation value $(0.1 \text { vol\% })^{41,42}$ Furthermore, the graphene-silica composite film (2-4 wt\% of graphene) is a transparent conductor with enhanced conductivity. ${ }^{39}$ This is because graphene sheets are well-dispersed in these composites. However, for using graphene-based composites for lithium-ion batteries, we need to produce highly condensed composites of micro-sized particle-like materials for these composites to be easily compatible with the process of commercial electrode fabrication at high packing density. Moreover, the synthetic process should be easily scalable.

In this study, we have proposed that a sol-gel process can serve as a facile platform for composite materials of high lithium storage capacity. These composite materials consist of silicon nanoparticles (SiNPs) coated with carbon, a small graphene network interconnecting these nanoparticles to form condensed micro-sized particles, and a large fraction of void spaces between nanoparticles and graphene networks in these composites. Since, Si/C composites are internally wired with graphene networks, they are denoted as Si/C-IWGNs hereafter. The Si/C-IWGN samples were simply prepared by carbonizing the composite gels formed in aqueous mixtures consisting of SiNPs and resorcinol (R)-formaldehyde (F) as the carbon precursor and a small amount of graphene oxide (GO) in onepot reactions as shown in Scheme 1. Various Si/C-IWGN samples were prepared with different contents of SiNPs (40 or $50 \mathrm{wt} \%$ ) and graphene (1, 5 and $10 \mathrm{wt} \%)$. Two types of gelation catalysts (C), $\mathrm{Na}_{2} \mathrm{CO}_{3}$ or $\mathrm{NH}_{4} \mathrm{OH}$, with different concentrations $(\mathrm{R} / \mathrm{C}$ ratio $=100-500$ in molar $)$ were used for forming composite gels. Various electrochemical responses of Si/C-IWGNs, such as cycling stability, volumetric as well as specific capacity, coulombic efficiency, and electrode thickness increase, are thoroughly compared with those of the following reference samples: (1) control composites, $\mathrm{Si} / \mathrm{C}$ composites, which were prepared without GO addition in the gel formation process in Scheme 1 and (2) commercial graphite. Finally, we have demonstrated a hybrid strategy to develop a reliable and lowcost anode material consisting of mixtures of high capacity $\mathrm{Si} / \mathrm{C}$ IWGNs and commercial graphite.

\section{Experimental}

\subsection{Preparation of $\mathrm{Si} / \mathrm{C}-\mathrm{IWGN}$ and $\mathrm{Si} / \mathrm{C}$ electrode materials}

To prepare Si/C-IWGN samples, GO was prepared by a modified Hummers method ${ }^{32,45}$ using commercial flakes of graphite provided by Asbury Carbons (230U Grade, High Carbon Natural Graphite $99^{+}$). Then, GO was diluted and an aqueous dispersion (0.6 wt\%) was prepared in deionized (DI) water through ultrasonication. In Table 1, we have summarized the details of the compositions used in the preparation of $\mathrm{Si} / \mathrm{C}$-IWGN and reference $\mathrm{Si} / \mathrm{C}$ composites.

To prepare Si/C-IWGN samples, we dispersed SiNPs (50$100 \mathrm{~nm}$ in diameter, KCC Corp. Ltd, Korea) in DI water in a vial through sonication. To this dispersion, we added a specific amount of GO solution. Then, this mixture was again subjected to sonication to obtain a homogeneous dispersion. To the mixture, we added resorcinol (R) and formaldehyde (F), which were used as carbon precursors. ${ }^{46}$ Finally, a gelation catalyst (C) $\left(\mathrm{Na}_{2} \mathrm{CO}_{3}\right.$ or $\left.\mathrm{NH}_{4} \mathrm{OH}\right)$ was added to the dispersion and it was stirred vigorously. The resorcinol/catalyst (R/C) molar ratio was varied in the range of 50-500. The mixture was stirred for $1 \mathrm{~h}$ at room temperature. Then, it was heated to $80{ }^{\circ} \mathrm{C}$ in a sealed vial under continuous stirring until the whole mixture formed a gel. The composite gel was further aged overnight at $90{ }^{\circ} \mathrm{C}$ to facilitate the cross-linking of the gel clusters. The composite gels obtained with the $\mathrm{Na}_{2} \mathrm{CO}_{3}$ catalyst were thoroughly washed and filtered thrice with DI water to remove the catalyst. The washing step was not required for composite gels obtained with the $\mathrm{NH}_{4} \mathrm{OH}$ catalyst because $\mathrm{NH}_{4}$ ions can be completely decomposed by the carbonization process. Subsequently, we carried out three solvent exchanges with isopropanol. After filtering, the

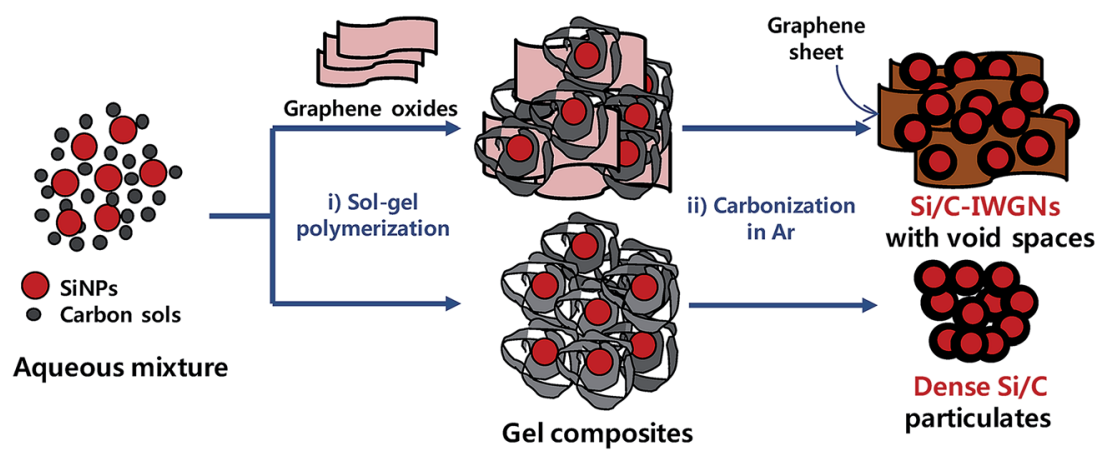

Scheme 1 Schematic diagram for the preparation of Si/C-IWGNs and reference Si/C composites. 
Table 1 Gel compositions and gelation catalysts used for the preparation of Si/C-IWGN and Si/C samples, and composite contents

\begin{tabular}{|c|c|c|c|c|c|c|c|c|c|}
\hline \multirow[b]{2}{*}{ Samples } & \multicolumn{4}{|c|}{ Gel compositions, $\mathrm{g}$} & \multicolumn{2}{|c|}{ Gelation cat., mL } & \multicolumn{3}{|c|}{ Composite contents ${ }^{c}, \mathrm{wt} \%$} \\
\hline & SiNPs & $\mathrm{R} / \mathrm{F}^{a}$ & $\mathrm{GO}^{b}$ & $\mathrm{H}_{2} \mathrm{O}$ & $\begin{array}{l}0.2 \mathrm{M} \mathrm{Na}_{2} \mathrm{CO}_{3} \\
\text { (R/C molar) }\end{array}$ & $\begin{array}{l}0.5 \mathrm{wt} \% \\
\mathrm{NH}_{4} \mathrm{OH}(\mathrm{R} / \mathrm{C} \text { molar })\end{array}$ & $\mathrm{Si}$ & $\mathrm{C}$ & $\mathrm{GS}^{d}$ \\
\hline $\mathrm{Si} / \mathrm{C}-1$ & 0.28 & $0.66 / 0.40$ & - & 22.3 & $0.6(50)$ & - & 46.3 & 56.0 & 0.0 \\
\hline Si/C-IWGN-1 & 0.28 & $0.65 / 0.39$ & 0.02 & 23.2 & $0.6(50)$ & - & 45.9 & 53.1 & 1.0 \\
\hline $\mathrm{Si} / \mathrm{C}-\mathrm{IWGN}-2$ & 0.35 & $0.76 / 0.47$ & 0.10 & 27.1 & $0.7(50)$ & - & 46.5 & 48.5 & 5.0 \\
\hline $\mathrm{Si} / \mathrm{C}-3$ & 0.35 & $0.55 / 0.33$ & - & 14.1 & - & $0.02(500)$ & 52.2 & 47.8 & 0.0 \\
\hline Si/C-IWGN-4 & 0.35 & $0.81 / 0.49$ & 0.02 & 20.8 & - & $0.16(100)$ & 44.4 & 54.6 & 1.0 \\
\hline Si/C-IWGN-5 & 0.35 & $0.81 / 0.49$ & 0.02 & 20.6 & - & $0.03(500)$ & 35.0 & 64.0 & 1.0 \\
\hline Si/C-IWGN-6 & 0.35 & $0.54 / 0.32$ & 0.02 & 20.3 & - & $0.10(100)$ & 52.9 & 46.1 & 1.0 \\
\hline
\end{tabular}

${ }^{a}$ Resorcinol/formaldehyde. ${ }^{b}$ Graphene oxide. ${ }^{c}$ Contents of Si and C (including GS) were determined from TGA profiles in Fig. 4 and S4. ${ }^{d}$ Graphene sheets.

gel was dried overnight in air at $80^{\circ} \mathrm{C}$. The dried composite gels were heated to $850{ }^{\circ} \mathrm{C}$ in a tube furnace under $100 \mathrm{~mL} \mathrm{~min}^{-1}$ of Ar flow; the ramp rate was kept at $5{ }^{\circ} \mathrm{C} \min ^{-1}$. To obtain $\mathrm{Si} / \mathrm{C}$ IWGN-1-6 composites, the temperature of the composites was maintained at $850{ }^{\circ} \mathrm{C}$ for $2 \mathrm{~h}$. The control samples, Si/C-1-3 composites, were prepared by following the same procedure used to prepare Si/C-IWGNs. But GO was not added to the gel solution in this process.

\subsection{Characterization}

(1) Material characterization. X-ray diffraction (XRD) patterns of the samples were recorded on an Ultima IV, Rigaku model D/MAX-50 kV system $\left(\mathrm{Cu}-\mathrm{K}_{\alpha}\right.$ radiation, $\left.\lambda=1.5418 \AA\right)$ and the structures of the samples were investigated using fieldemission scanning electron microscopy (FE-SEM, JEOL JSM$35 \mathrm{CF}$ operated at $10 \mathrm{kV}$ ) and transmission electron microscopy (TEM, JEOL JEM-2010 operated at $200 \mathrm{kV}$ ). In order to investigate the microstructure of cross-sections of sample particles by SEM and energy-dispersive X-ray spectroscopy (EDS) elemental mapping, samples were mounted in epoxy resin and cut into thin slices using a diamond cutter. The Si and C contents in the samples were determined by thermal gravimetric analysis (TGA) run to $800{ }^{\circ} \mathrm{C}$ at a ramp rate of $10{ }^{\circ} \mathrm{C} \mathrm{min}^{-1}$ under air flow. The contents of graphene sheets (GSs) in the Si/C-IWGN samples given in Table 1 were estimated based on the weight loss of dried GO by TGA run under $\mathrm{N}_{2}$ flow. X-ray photoelectron spectroscopy (XPS) was conducted to analyze the surface chemical compositions of samples on a Thermo Electron Corporation spectrometer with $\mathrm{Al} \mathrm{K}_{\alpha}(1486.6 \mathrm{eV})$ radiation. Fourier-transform infrared (FTIR) spectra were collected in the range of 400$4000 \mathrm{~cm}^{-1}$ using a Thermo scientific Nicolet 380 spectrometer (KBr pellets). Raman spectra were obtained using a WITec alpha 300R spectrometer equipped with a $532 \mathrm{~nm}$ laser. Sheet resistances and conductivities of coated electrodes were measured by using a four-point probe technique with an electrode separation of $1 \mathrm{~mm}$ using a Keithley 2400 sourcemeter.

(2) Electrochemical responses. The electrochemical responses of the samples were tested using CR2032 coin-type cells assembled in an argon-filled glove box with Li foil as the counter electrode. The working electrode was prepared by casting a paste that consisted of the active material (Si/C-IWGN1-6 or Si/C-1-3 or Si-Gr), conductive additive (Super P Li, Timcal Ltd) and polyvinyl alcohol (PVA) ${ }^{47}$ binder (dissolved in anhydrous dimethyl sulfoxide) with a mass ratio of $8: 1: 1$ onto a copper foil current collector using a Meyer-Bar coating device (Kipae E\&T, Korea). A hybrid sample, Si-Gr, was prepared by mixing Si/C-IWGN-6 with commercial graphite with a mass ratio of $4: 6$. The working electrode of commercial graphite was prepared similarly except for the different binder (PVdF). The coated electrodes were roll-pressed under a constant compression ratio (=target thickness after pressing/coating thickness of a paste) and then vacuum dried at $80{ }^{\circ} \mathrm{C}$ for $12 \mathrm{~h}$. The resulting electrode thickness was about $20-40 \mu \mathrm{m}$ with a total mass loading of $1.5-2.0 \mathrm{mg} \mathrm{cm} \mathrm{cm}^{-2}$ (3.43 $\mathrm{mg} \mathrm{cm} \mathrm{cm}^{-2}$ for graphite). A Celgard 2400 polypropylene membrane was used as the separator. 1.0 $\mathrm{M} \mathrm{LiPF} 6$ in ethylene carbonate (EC)/ethyl methyl carbonate (EMC)/diethylcarbonate (DEC) with a volume ratio of 3 : 4 : 3 (PANAX ETEC Co., Ltd, Korea) containing 10 vol\% fluoroethylene carbonate (FEC) was used as the electrolyte for silicon-containing composites. 1.0 $\mathrm{M} \mathrm{LiPF}_{6}$ in an EC/EMC/DEC with a volume ratio of $3: 4: 3$ was used as the electrolyte for graphite. Electrochemical cycling and rate tests were conducted in a cut-off voltage range of 1.5-0.02 V (2.0-0.005 $\mathrm{V}$ for graphite) vs. $\mathrm{Li} / \mathrm{Li}^{+}$and cyclic voltammetry (CV) tests were carried out at a scan rate of $0.1 \mathrm{mV} \mathrm{s}^{-1}$ on a galvanostat/potentiostat system (WonATech Co., Ltd, Korea). The electrode thickness changes were measured by SEM of electrode cross-sections before and after the cycling test.

\section{Results and discussion}

\subsection{Structures of $\mathrm{Si} / \mathrm{C}$ and $\mathrm{Si} / \mathrm{C}-\mathrm{IWGN}$ composites}

In Fig. 1, SEM and TEM images of Si/C-IWGN-3 and Si/C-IWGN6 are presented. All the Si/C-IWGN samples had the shape of a thick disc, which contained the condensed particles (also see Fig. S1 in the ESI $\dagger$ ). At high magnification, the SEM images of particle edges reveal that graphene sheets/stacks and carbon- 

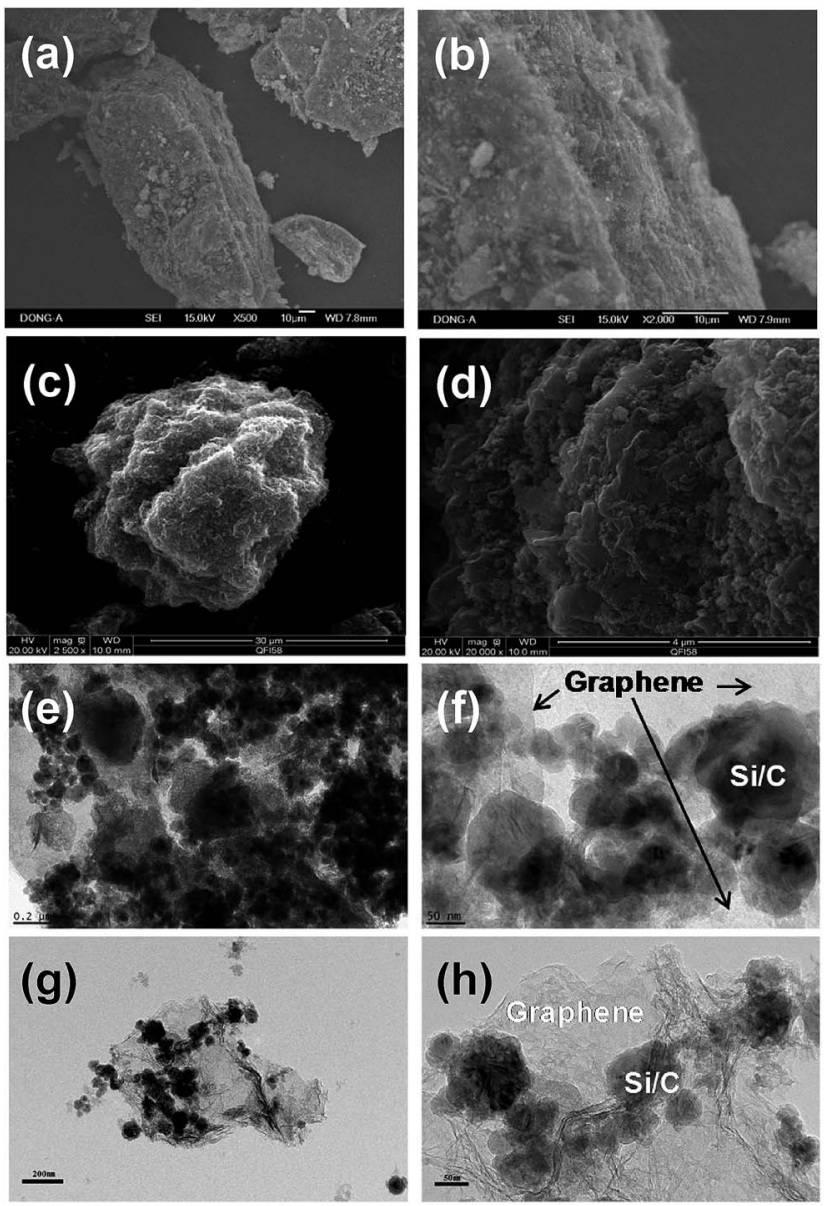

Fig. 1 SEM images of ( $a$ and b) Si/C-IWGN-3 and (c and d) Si/C-IWGN-6, and TEM images of (e and f) Si/C-IWGN-3 and ( $g$ and h) Si/C-IWGN-6.

coated SiNPs are aligned and densely packed in an alternating fashion. On the other hand, the SEM images of Si/C composites without graphene networks show spherical carbon-coated silicon particulates (Fig. S2 $†$ ). TEM images of SiNPs, Si/C-1 and Si/C-IWGN samples are also shown in Fig. 1 and Fig. S1. $\dagger$ SiNPs, having diameters in the range of 50-100 nm (Fig. S1e†), are evenly coated with carbon in Si/C composites (Fig. S1f and S3†). As seen in the TEM images of Si/C-IWGN samples, spherical $\mathrm{Si} / \mathrm{C}$ particles are distributed in between graphene sheets. Furthermore, a large fraction of void spaces are not only present between $\mathrm{Si} / \mathrm{C}$ particles but they are also present between $\mathrm{Si} / \mathrm{C}$ particles and graphene sheets. However, most of these $\mathrm{Si} / \mathrm{C}$ particles are in intimate contact with graphene electrical wires in $\mathrm{Si} / \mathrm{C}$ particles. These structural features of the Si/C-IWGN are highly conducive in achieving cycling stability, despite the huge volume changes in silicon-based composites.

In order to comprehensively investigate the microstructure of inside particles, we observed the cross-sections by SEM. In Fig. 2a and $\mathrm{b}$, the cross-section images of Si/C-2 particles are displayed. The spherical $\mathrm{Si} / \mathrm{C}$ particles are densely packed as there are tiny void spaces between these particles. The SiNPs in Si/C-2 are evenly coated with carbon layers (Fig. 2 b). As shown in the SEM image of Si/C-IWGN-3 particles in Fig. 2c, white spots
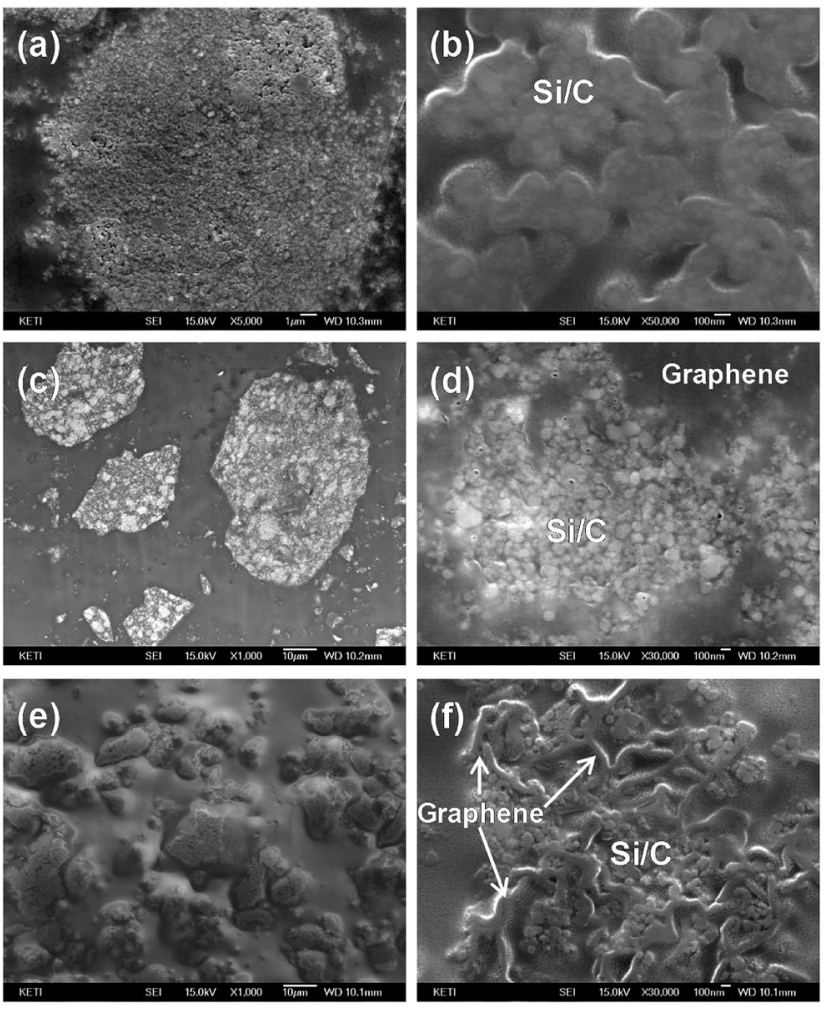

Fig. 2 SEM images of particle cross-sections; ( $a$ and b) Si/C-2, (c and d) Si/C-IWGN-3 and (e and f) Si/C-IWGN-6.

are surrounded by thin layers that are dark-gray in color. Fig. 2d is a highly magnified SEM image of Si/C-IWGN-3 particles. In Fig. 2d, the white spots are Si/C aggregates surrounded and/or covered by thin layers of graphene sheets, which are further elucidated by energy-dispersive X-ray spectroscopy (EDS) mapping of Si and C (Fig. 3). In Fig. 2e, we have presented the SEM image of the cross-section of Si/C-IWGN-6 particles, which
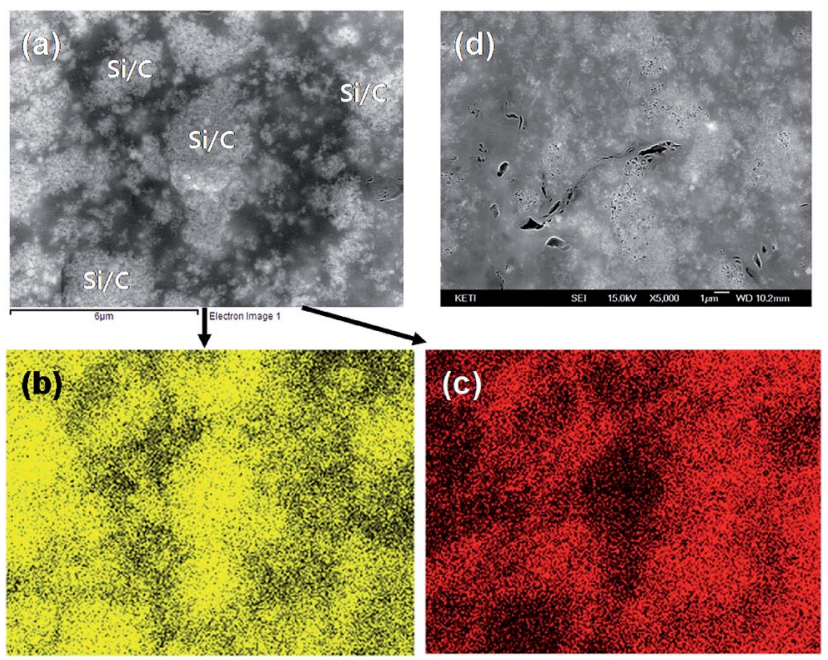

Fig. 3 SEM images of ( $a$ and $d$ ) Si/C-IWGN-3 and EDS mapping of image (a) for (b) silicon and (c) carbon. 
was prepared using $\mathrm{NH}_{4} \mathrm{OH}$ as the gelation catalyst. In this figure, we observe several composite particles having a size of $15 \mu \mathrm{m}$. Fig. 2f displays a single particle of this composite material under high magnification. As shown in Fig. 2f, relatively thick graphene stacks are randomly distributed around $\mathrm{Si}$ / C particles, which are characterized by a large fraction of void spaces. The particle density of $\mathrm{Si} / \mathrm{C}-\mathrm{IWGN}-3$ prepared using $\mathrm{Na}_{2} \mathrm{CO}_{3}$ as the gelation catalyst must be greater than that of $\mathrm{Si}$ / C-IWGN-6 prepared with $\mathrm{NH}_{4} \mathrm{OH}$. Thus, with this novel sol-gel based synthetic strategy, we dispersed graphene sheets to form electrical networks and graphene-induced void spaces in the composites.

In Table 1, we have presented the Si contents determined by TGA of samples (see Fig. $4 \mathrm{a}$ and Fig. $\mathrm{S} 4 \dagger$ ). The Si contents have been divided into two different ranges of 35.0-46.0 wt\% and 50.0-52.2 wt\%, and the Si content was controlled by the mass ratio of SiNPs/R used in the gelation mixtures. As shown in Fig. 4, the GS contents of samples in Table 1 were calculated by applying the mass loss (i.e., $45 \mathrm{wt} \%$ at $150-800{ }^{\circ} \mathrm{C}$ ) of dried GO in TGA to the mass of GO initially present in the gelation mixture. TGA was performed up to a temperature of $800{ }^{\circ} \mathrm{C}$ under $\mathrm{N}_{2}$. The GS contents in the samples were varied by the amount of GO added in the gelation mixture. They were estimated to be in the range of 1-10 $\mathrm{wt} \%$. In the XRD patterns of samples (see Fig. S5 ${ }^{\dagger}$ ), we observed only crystalline Si diffraction peaks at $2 \theta=28.6^{\circ}, 47.5^{\circ}$, and $56.3^{\circ}$ corresponding to the (111), (220), and (311) planes, respectively. These diffraction
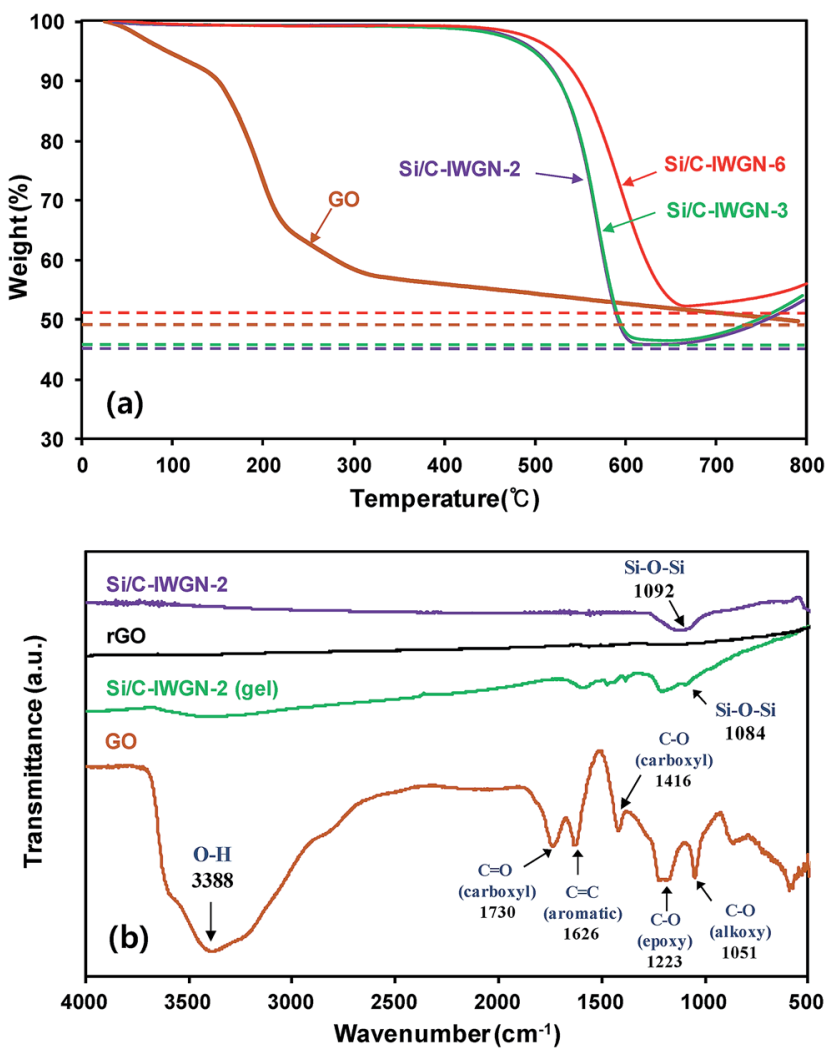

Fig. 4 (a) TGA profiles of Si/C-IWGN samples (run in air flow) and GO (run in $\mathrm{N}_{2}$ flow) and (b) FTIR spectra of samples. peaks were observed without any graphitic carbon phase at around $2 \theta=26.4^{\circ}$ even when the GS content in the Si/C-IWGN-3 composite was as high as $10 \mathrm{wt} \%$. This indicates that GS sheets are highly dispersed in composites that do not form a thick crystalline graphitic phase, which is usually observed in $\mathrm{Si}$ graphene composites annealed at high temperature. ${ }^{32-34}$

The structural change associated with the formation of the Si/C-IWGN was further investigated using FTIR and Raman spectroscopy. FTIR spectra in Fig. 4b indicated that various bands of oxygen functional groups present in GO were substantially decreased in intensity in the Si/C-IWGN-2 (gel) and they were not detected in rGO (GO reduced in Ar flow at $850{ }^{\circ} \mathrm{C}$ for $2 \mathrm{~h}$ ) and in $\mathrm{Si} / \mathrm{C}-\mathrm{IWGN}-2$. This suggests that GO was partially reduced during the sol-gel reaction and it was further reduced to graphene after carbonization at high temperature. ${ }^{32}$ Raman spectra showed intense peaks at about 1350 and $1590 \mathrm{~cm}^{-1}$, corresponding to the well-defined $\mathrm{D}$ and $\mathrm{G}$ bands, respectively (Fig. S6 $\dagger$ ). The $I_{\mathrm{D}} / I_{\mathrm{G}}$ ratio of rGO (1.04) was higher than that of GO (0.99), suggesting that the disordering portion of the twodimensional carbon backbone was increased. The same trend was also observed from the conversion of Si/C-IWGN-2 (gel) to Si/C-IWGN by carbonization due to the partially disordered crystal structure of graphene sheets.

The surface compositions of SiNPs in composites were investigated by XPS, and the Si $2 \mathrm{p}$ spectra are presented in Fig. S7. $\uparrow$ The parent SiNPs showed a strong Si 2p peak at $99.8 \mathrm{eV}$, which was associated with bulk $\mathrm{Si}^{0}$, while a small peak at $103.4 \mathrm{eV}$ was attributed to a thin native $\mathrm{SiO}_{x}$ layer. ${ }^{47}$ In the $\mathrm{Si} / \mathrm{C}$ IWGN samples, the peak intensity at $99.8 \mathrm{eV}$, which was associated with $\mathrm{Si}^{0}$, substantially decreased. On the other hand, there was an increase in the intensity at $104.0 \mathrm{eV}$, which is associated with $\mathrm{SiO}_{x}$. This is because during the sol-gel reaction, the surface of SiNPs is partially oxidized to $\mathrm{SiO}_{x}$ (mainly $\mathrm{SiO}_{2}$ ) under slightly alkaline conditions. The relative intensity of the $\mathrm{SiO}_{x}$ peak to the $\mathrm{Si}^{0}$ peak is more prominent in samples prepared at a higher $\mathrm{R} / \mathrm{C}$ ratio. Thus the surface oxide layer on $\mathrm{Si} / \mathrm{C}$-IWGN-3, which was prepared at an $\mathrm{R} / \mathrm{C}$ molar ratio of 50 using $\mathrm{Na}_{2} \mathrm{CO}_{3}$ as the gelation catalyst, was thicker than that on $\mathrm{Si} / \mathrm{C}-\mathrm{IWGN}-4$ and $\mathrm{Si} / \mathrm{C}-\mathrm{IWGN}-5$, which were prepared with $\mathrm{NH}_{4} \mathrm{OH}$ as the gelation catalyst at an $\mathrm{R} / \mathrm{C}$ molar ratio of 100 and 500 , respectively.

\subsection{Electrochemical responses of $\mathrm{Si} / \mathrm{C}$ and $\mathrm{Si} / \mathrm{C}-\mathrm{IWGN}$ composites}

In Fig. 5, we have compared the galvanostatic charge/discharge voltage profiles of $\mathrm{Si} / \mathrm{C}$ and $\mathrm{Si} / \mathrm{C}-\mathrm{IWGN}$ samples for the first cycle. In all the composites, the voltage slopes between 1.5 and $0.2 \mathrm{~V}$ appeared at the first discharge. These voltage slopes were attributed to the formation of an irreversible solid-electrolyte interface (SEI) film and the decomposition of the surface oxide layer $\left(\mathrm{SiO}_{x}\right)^{47,48}$ This was followed by the appearance of long voltage plateaus between 0.2 and $0.02 \mathrm{~V}$, which was attributed to the alloying reaction between $\mathrm{Li}^{+}$and $\mathrm{Si}^{6}{ }^{6}$ At the first charge, the de-alloying reaction appeared at a sloping voltage plateau of 0.2 to $0.6 \mathrm{~V}$. At a current of $100 \mathrm{~mA} \mathrm{~g}^{-1}$, the reference samples, Si/C1, $\mathrm{Si} / \mathrm{C}-2$, and $\mathrm{Si} / \mathrm{C}-3$, showed the first discharge/charge 

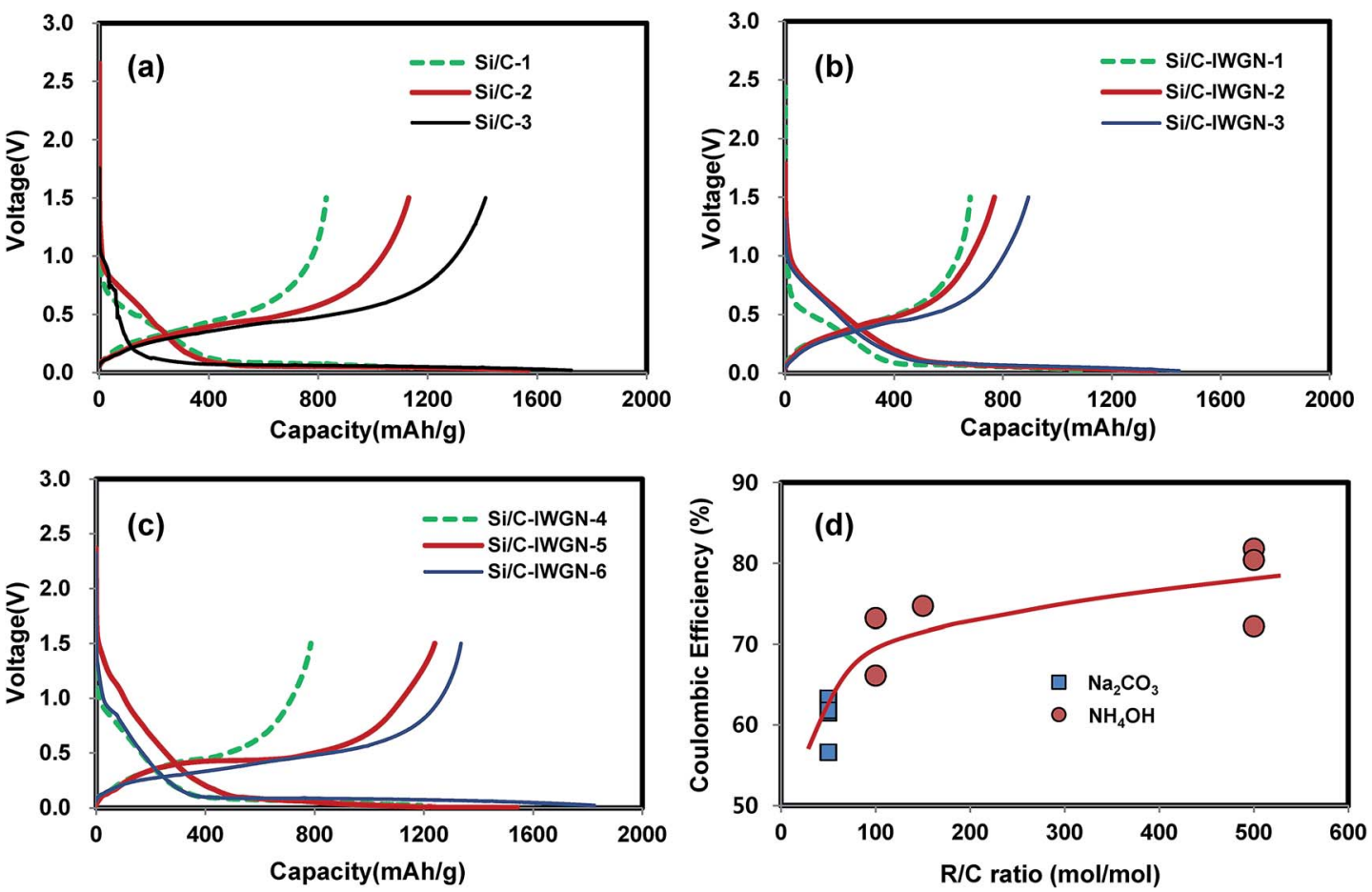

Fig. 5 Voltage profiles of (a) Si/C-1-3, (b) Si/C-IWGN-1-3, (c) Si/C-IWGN-4-6 and the first cycle coulombic efficiencies of samples as a function of $\mathrm{R} / \mathrm{C}$ ratio.

capacities of 1284/813, 1567/1131 and 1725/1411 $\mathrm{mA} \mathrm{h} \mathrm{g}{ }^{-1}$, respectively. The corresponding coulombic efficiencies (CEs) were $63.3,72.2$, and $81.8 \%$, respectively. At a current of $100 \mathrm{~mA} \mathrm{~g}^{-1}$, the composites, Si/C-IWGN-1, Si/C-IWGN-2, and Si/ C-IWGN-3, exhibited the first discharge/charge capacities of $1106 / 680,1358 / 769$ and $1447 / 894 \mathrm{~mA} \mathrm{~h} \mathrm{~g}^{-1}$, with the corresponding CEs being 61.5, 56.6, and $61.8 \%$, respectively. The composites, Si/C-IWGN-4, Si/C-IWGN-5, and Si/C-IWGN-6, exhibited the first discharge/charge capacities of $1190 / 787$, $1542 / 1240$, and $1825 / 1336 \mathrm{~mA} \mathrm{~h} \mathrm{~g}^{-1}$, with the corresponding CEs being 66.1, 80.4, and $73.2 \%$, respectively.

As seen in Fig. 5d, the composites, Si/C-1 and Si/C-IWGN-13 , which were prepared with the $\mathrm{Na}_{2} \mathrm{CO}_{3}$ catalyst at an $\mathrm{R} / \mathrm{C}$ ratio of 50, exhibited relatively low CEs in the range of $56.6-63.3 \%$ in the first cycle. On the other hand, Si/C-2, Si/C-3, and Si/C-IWGN5 , which were prepared using the $\mathrm{NH}_{4} \mathrm{OH}$ catalyst at an $\mathrm{R} / \mathrm{C}$ ratio of 500, showed CEs in a higher range of 72.2-81.8\%. Si/C-IWGN4 and $\mathrm{Si} / \mathrm{C}-\mathrm{IWGN}-6$, which were prepared using the $\mathrm{NH}_{4} \mathrm{OH}$ catalyst at an $\mathrm{R} / \mathrm{C}$ ratio of 100 , exhibited CEs in an intermediate range of $66.1-73.2 \%$. Fig. $5 \mathrm{~d}$ represents the plot of CEs against $\mathrm{R} / \mathrm{C}$ molar ratio. From this plot, we deduce that a larger R/C ratio can be used to gain higher CEs in the first cycle provided the gelation rate is not affected significantly. Under hydrothermal conditions, the surface of SiNPs in the composites is oxidized ${ }^{38}$ to $\mathrm{SiO}_{x}$ as the level of oxidation is dependent on the $\mathrm{R} / \mathrm{C}$ ratio, as evinced in the Si 2p XPS spectra shown in Fig. S7. $\dagger$ The formation of the SEI layer is known to cause irreversible capacity loss in the first cycle. In addition, the surface oxide layer is subjected to irreversible lithiation reactions, ${ }^{47,48}$ which are also responsible for irreversible capacity loss to some extent in the first cycle.

Fig. $6 \mathrm{a}$ and $\mathrm{b}$ display the cycling performances (in terms of discharge, i.e., lithiation, capacities) and CEs, respectively, of the reference $\mathrm{Si} / \mathrm{C}$ samples. The samples were exposed initially to either three or five cycles at a current of $100 \mathrm{~mA} \mathrm{~g}^{-1}$.
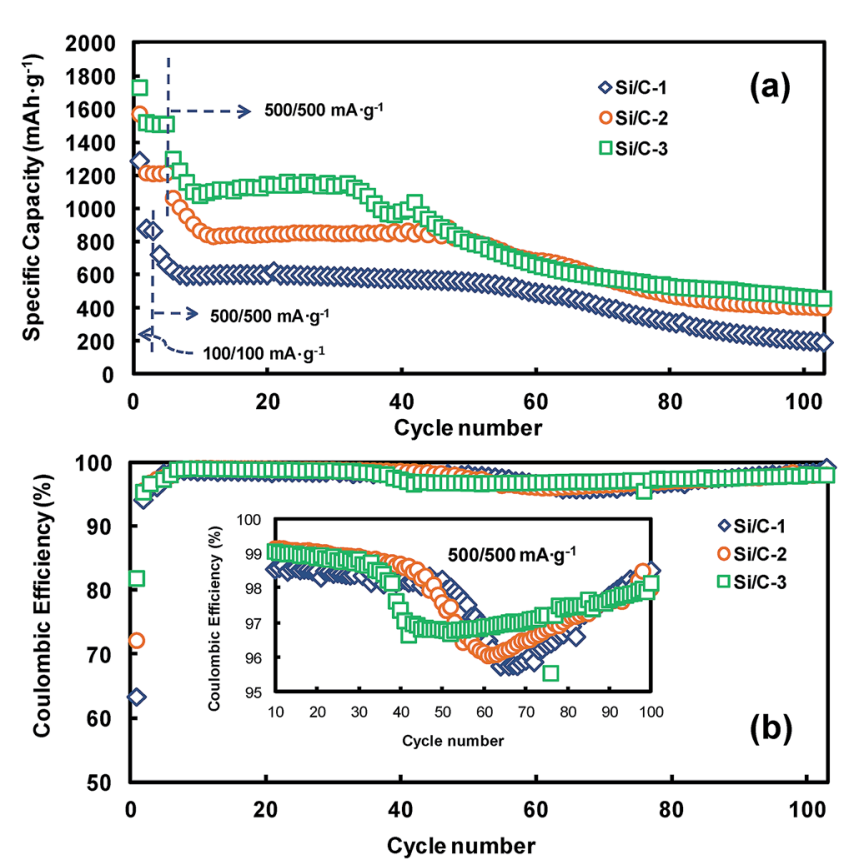

Fig. 6 (a) Cycling performances and (b) coulombic efficiencies of Si/ C-1-3 cycled in the cut-off range of $0.02-1.5 \mathrm{~V}$. 
Thereafter, they were subjected to 100 cycles at a current of $500 \mathrm{~mA} \mathrm{~g}^{-1}$. The Si/C-3 (Si content $=52.2 \mathrm{wt} \%$ ) exhibited the

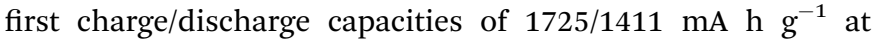
an applied current of $100 \mathrm{~mA} \mathrm{~g}^{-1}$. At an applied current of $500 \mathrm{~mA} \mathrm{~g}^{-1}$, we observed that the capacity of the composite was in the range of $1100-1150 \mathrm{~mA} \mathrm{~h} \mathrm{~g}^{-1}$ until the completion of 30 cycles. However, the capacity of the composite started fading rapidly after the $30^{\text {th }}$ cycle. The $\mathrm{Si} / \mathrm{C}-2$ ( $\mathrm{Si}$ content $=46.3 \mathrm{wt} \%$ ) composite exhibited the first charge/discharge capacities of $1567 / 1131 \mathrm{~mA} \mathrm{~h} \mathrm{~g}^{-1}$ at a current of $100 \mathrm{~mA} \mathrm{~g}^{-1}$. By further cycling of $\mathrm{Si} / \mathrm{C}-2$ at a current of $500 \mathrm{~mA} \mathrm{~g}^{-1}$, a stable cycling performance was achieved at a reversible capacity of 825$840 \mathrm{~mA} \mathrm{~h} \mathrm{~g}^{-1}$ for up to 45 cycles. But the capacity of $\mathrm{Si} / \mathrm{C}-2$ also faded to $332 \mathrm{~mA} \mathrm{~h} \mathrm{~g}{ }^{-1}$ after 100 cycles. The cycling behavior of $\mathrm{Si} / \mathrm{C}-1$ was similar to those of $\mathrm{Si} / \mathrm{C}-2$ and $\mathrm{Si} / \mathrm{C}-3$. However, compared with $\mathrm{Si} / \mathrm{C}-2$, Si/C-1 (Si content $=45.7 \mathrm{wt} \%$ ), whose $\mathrm{Si}$ content was similar to that of $\mathrm{Si} / \mathrm{C}-2$, showed much lower reversible capacity $\left(875 \mathrm{~mA} \mathrm{~h} \mathrm{~g}^{-1}\right.$ at $\left.100 \mathrm{~mA} \mathrm{~g}^{-1}\right)$ and much lower CE $(63.3 \%)$ in the first cycle. This was because the SiNPs in $\mathrm{Si} / \mathrm{C}-1\left(\mathrm{R} / \mathrm{C}\right.$ ratio $=50$ with $\left.\mathrm{C}=\mathrm{Na}_{2} \mathrm{CO}_{3}\right)$ underwent more severe surface oxidation than those in $\mathrm{Si} / \mathrm{C}-2(\mathrm{R} / \mathrm{C}$ ratio $=500$ with $\mathrm{C}=\mathrm{NH}_{4} \mathrm{OH}$ ).

As shown in Fig. 6b and its inset, at a current of $500 \mathrm{~mA} \mathrm{~g}^{-1}$, the CEs of Si/C samples decreased from the cycle in which their capacity started fading. This indicates that abrupt irreversible events, such as electrochemical and structural changes occurred in Si/C electrodes. To support this, electrode thickness changes were measured by SEM on the Si/C-2 and Si/C-3 electrodes in their pristine, first-lithiated, and first-delithiated forms. As shown in Fig. 7, after the first lithiation, the thickness of $\mathrm{Si} / \mathrm{C}-2$ and $\mathrm{Si} / \mathrm{C}-3$ electrodes increased by $110 \%$ and $117 \%$, respectively, while after the first delithiation, the thickness of these electrodes increased by 74 and $70 \%$, respectively, over the pristine one. The sharp increase in the thickness of $\mathrm{Si} / \mathrm{C}-2$ and $\mathrm{Si} / \mathrm{C}-3$ electrodes with the progression of cycles was ascribed to the cause of capacity fading, as they underwent electrode pulverization, leading to the loss of electrical contacts between active materials as well as between active materials and current collector. In summary, the Si/C samples in which SiNPs are quite evenly coated with carbon layers (see Fig. S1-S3†) still suffer from capacity fading, which is accompanied by a sharp increase in electrode thickness. Hence, it is certain that a simple carbon coating, which is mostly done to enhance the electrical conductivity of silicon, is not enough to achieve long-term cycling stability of silicon-based composites.

Fig. 8a and b show the cycling performances and CEs of Si/CIWGN-1-3 series samples, respectively. The samples were exposed to the initial three cycles at an applied current of $100 \mathrm{~mA} \mathrm{~g}^{-1}$. Then, they were cycled to additional 100 cycles at $500 \mathrm{~mA} \mathrm{~g}^{-1}$. The reversible discharge capacities in the second cycle of Si/C-IWGN-1, Si/C-IWGN-2, and Si/C-IWGN-3 were, 738, 879, and $994 \mathrm{~mA} \mathrm{~h} \mathrm{~g}{ }^{-1}$, respectively. On further cycling at $500 \mathrm{~mA} \mathrm{~g}^{-1}$, the corresponding discharge capacities were stabilized in the tenth cycle at 470,667 and $749 \mathrm{~mA} \mathrm{~h} \mathrm{~g}^{-1}$. At the end of the $100^{\text {th }}$ cycle at $500 \mathrm{~mA} \mathrm{~g}^{-1}$, the composites showed capacity retentions of $90.2,84.6$ and $85.2 \%$, respectively. As seen in Fig. 6, the reference sample, Si/C-1, showed the corresponding capacity retention of only $32.1 \%$. At $500 \mathrm{~mA} \mathrm{~g}^{-1}$, the CEs of Si/C-IWGN-1-3 increased from $98.1-98.8 \%$ in the $10^{\text {th }}$ cycle to above $99 \%$ in the $100^{\text {th }}$ cycle as shown in Fig. $8 \mathrm{~b}$ and its inset. Thus, the Si/C-IWGN-1-3 composites with graphene networks showed much better cycling stability than Si/C-1. Since the series samples of $\mathrm{Si} / \mathrm{C}-1$ and $\mathrm{Si} / \mathrm{C}-\mathrm{IWGN}-1-3$ were prepared under identical conditions using the same amount of Si contents, the enhanced cycling stabilities of Si/C-IWGN-1-3 could be ascribed to the presence of graphene networks in those composites. For the series of $\mathrm{Si} / \mathrm{C}-1$ and $\mathrm{Si} / \mathrm{C}-\mathrm{IWGN}-1-3$, the sheet resistances and conductivities of pristine electrodes are presented in Table $\mathrm{S} 1$ and Fig. S8. $\dagger$ The sheet resistance increased with increasing graphene content in the samples. The sheet resistances of Si/C-IWGN-2 and Si/C-IWGN-3, whose graphene contents were 5 and $10 \mathrm{wt} \%$, respectively, were significantly higher than those of other samples. Therefore, the conductivities of Si/C-IWGN-2 and Si/C-IWGN-3 were less than
Pristine

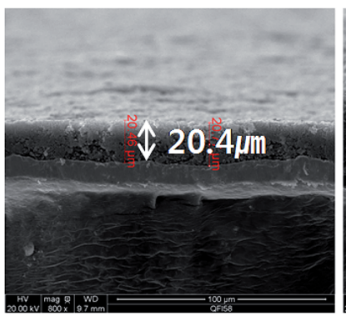

(b)
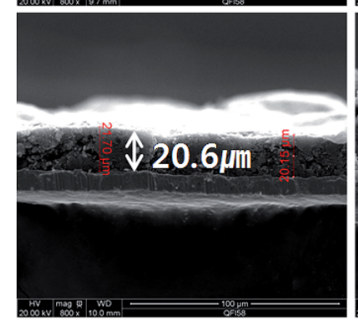

1st lithiation
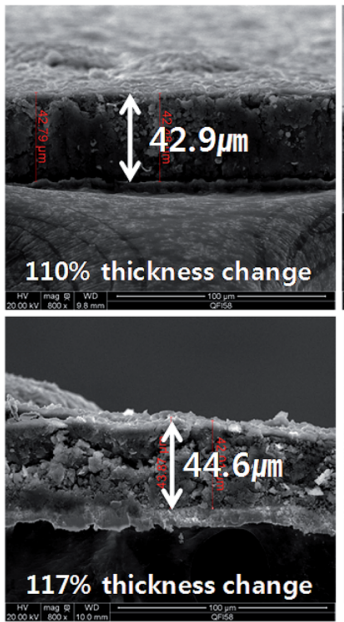

$\mathbf{1}^{\text {st }}$ delithiation

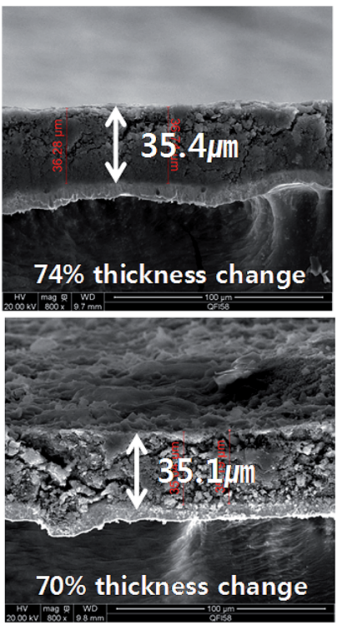

Fig. 7 SEM images of electrode cross-sections of (a) Si/C-2 and (b) Si/C-3 for their pristine and after the first lithiation and delithiation. 

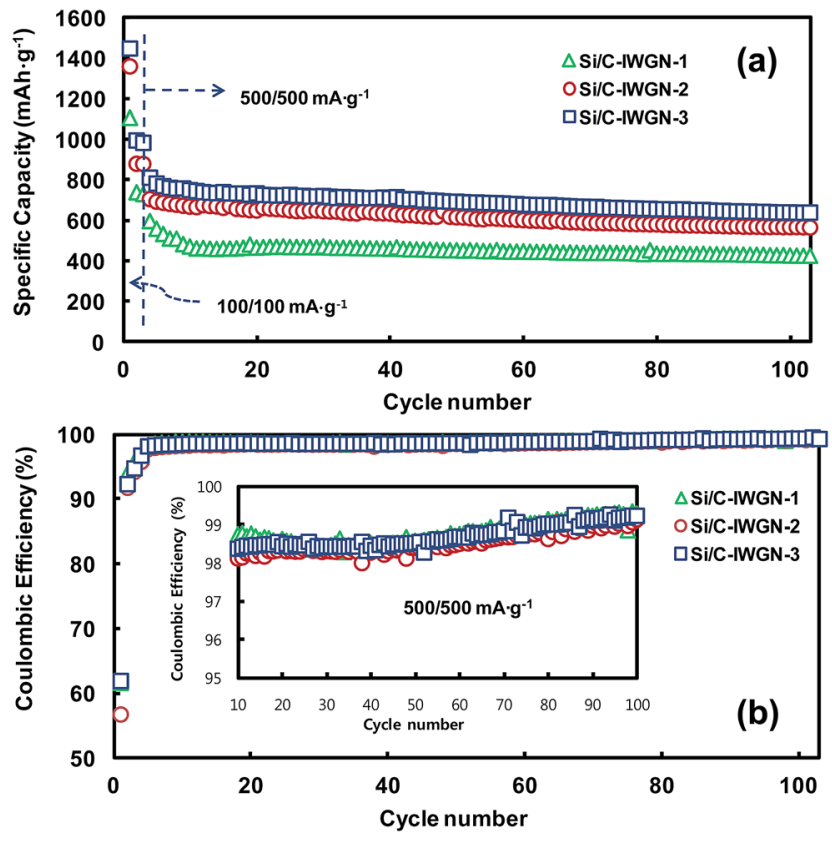

Fig. 8 (a) Cycling performances and (b) coulombic efficiencies of $\mathrm{Si} / \mathrm{C}-\mathrm{IWGN}-1-3$ cycled in the cut-off range of $0.02-1.5 \mathrm{~V}$.

about two fold when compared with those of Si/C-1 and Si/CIWGN-1 composites, whose graphene contents were 0 and 1 $\mathrm{wt} \%$, respectively. Since the same electrode formulations were applied to the entire series of samples, the difference in electrode resistance can be attributed to the difference in active material properties. These results are more or less expected when one peruses through the apparent electrode densities in Fig. 1-3 (TEM images and SEM images of the cross-section of a particle). Owing to the presence of graphene networks in composites, a large fraction of void spaces are observed between $\mathrm{Si} / \mathrm{C}$ particles and graphene sheets as seen in the TEM images in Fig. 1. As shown in Fig. 2 and 3, the void spaces are more clearly visible in the SEM images of particle cross-sections. On the other hand, Si/C particles are more densely packed in Si/C-1 (Fig. 2a). Furthermore, although the aggregates of small sized $\mathrm{Si} / \mathrm{C}$ are distributed over the bulk particles, they are connected by graphene sheets in the micrometer-sized particles of Si/CIWGN-3 (Fig. 2 and 3). Hence, when compared with $\mathrm{Si} / \mathrm{C}-1$, the presence of graphene networks in the Si/C-IWGN decreases particle density and electrical conductivity. However, under the circumstances of huge volume expansions of silicon through repeated cycling, the void spaces in Si/C-IWGNs accommodate volume variations, and graphene networks maintain electrical networks in composites. To support this hypothesis, we measured the changes in the thickness of $\mathrm{Si} / \mathrm{C}-1$ and $\mathrm{Si} / \mathrm{C}-$ IWGN-2 electrodes before and after cycling. As shown in Fig. S9, $\dagger$ the thickness of Si/C-1 increased by $62.2-77.5 \%$ over the pristine sample, while that of Si/C-IWGN-2 increased by only $21 \%$ after being subjected to 100 cycles at $500 \mathrm{~mA} \mathrm{~g}^{-1}$. It is interesting to note that the increase in the thicknesses of cycled Si/C-1 and Si/C-IWGN-2 is comparable to those of first-delithiated Si/C-2 and Si/C-IWGN-3 (see Fig. 10 below), respectively. Therefore, the graphene networks present in Si/C-IWGN-1-3 were found to be quite effective in enhancing the cycling stability of silicon-based composites.

In Si/C-IWGN-1, a small amount of graphene as low as $1 \mathrm{wt} \%$ was sufficient to effectively stabilize the cycling performance (Fig. 8a). Therefore, Si/C-IWGN-4-6 composites were prepared to contain about $1 \mathrm{wt} \%$ of graphene but different amounts of silicon with $\mathrm{NH}_{4} \mathrm{OH}$ as the gelation catalyst (see Table 1) at two different $\mathrm{R} / \mathrm{C}$ ratios. Fig. 9a and $\mathrm{b}$ show the cycling performances and CEs of the Si/C-IWGN-4-6 samples, respectively. At a current of $100 \mathrm{~mA} \mathrm{~g}^{-1}$, the composites, Si/C-IWGN-4, Si/CIWGN-5, and Si/C-IWGN-6 exhibited reversible discharge capacities in the range of 1530-1560, 1330-1360, and 870-896 $\mathrm{mA} \mathrm{h} \mathrm{g}{ }^{-1}$, respectively. On further cycling at $500 \mathrm{~mA} \mathrm{~g}^{-1}, \mathrm{Si} / \mathrm{C}-$ IWGN-4, Si/C-IWGN-5, and Si/C-IWGN-6 showed stabilized discharge capacities of 656,784 , and $855 \mathrm{~mA} \mathrm{~h} \mathrm{~g}^{-1}$, respectively, at the $15^{\text {th }}$ cycle; the capacity retentions of Si/C-IWGN-4, Si/CIWGN-5, and Si/C-IWGN-6 were 84.8, 87.0, and 83.4\%, respectively, at the $100^{\text {th }}$ cycle. On the other hand, the corresponding capacity retentions of reference $\mathrm{Si} / \mathrm{C}-2$ and $\mathrm{Si} / \mathrm{C}-3$ were only 47.5 and $41.3 \%$, respectively (Fig. 6). The CEs of Si/C-IWGN-4-6 increased to approach $99.2-99.4 \%$ at the end of the cycle. However, when the current density was increased from 100 to $500 \mathrm{~mA} \mathrm{~g}^{-1}$, Si/C-IWGN-5 and Si/C-IWGN-6 showed a steep drop in capacity compared to other Si/C-IWGN samples. This drop in capacity at high current could be attributed to low electrode conductivities due to low material densities, which are apparent in Fig. 2. In general, an active material of higher density has to be used to obtain electrodes with higher volumetric capacity. ${ }^{49}$ On the other hand, the void space in the composite, which inherently decreases its density, is advantageous in maintaining the cycling stability of silicon, which undergoes a large volume expansion in the electrode. ${ }^{16,17,19,20,29,50-52}$ Hence, the material
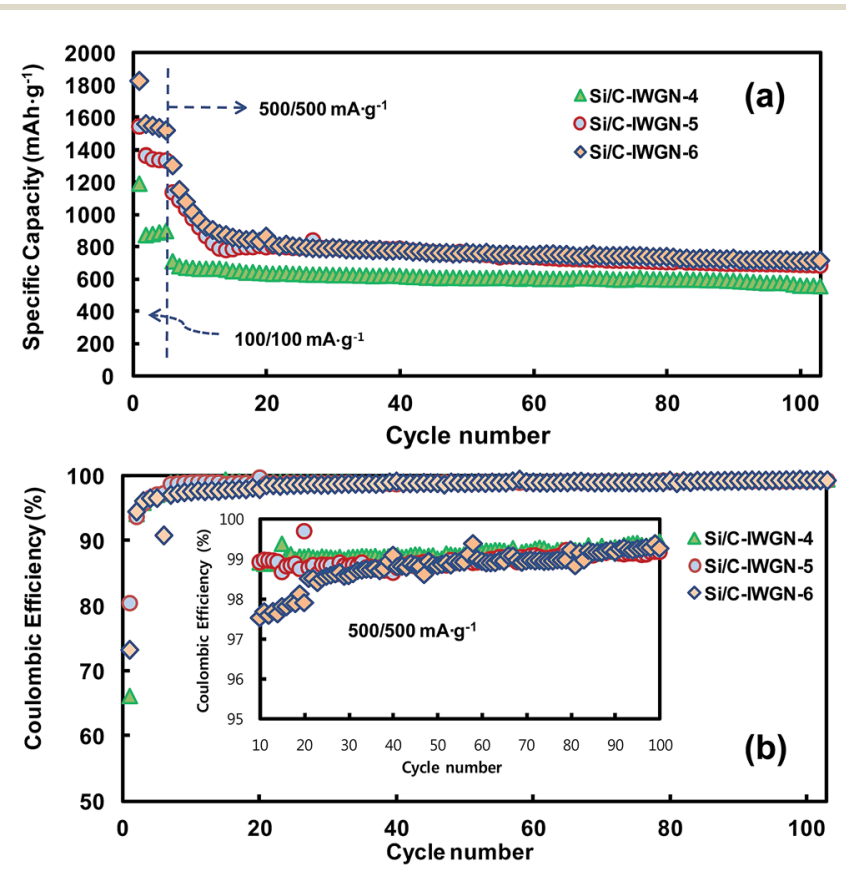

Fig. 9 (a) Cycling performances and (b) coulombic efficiencies of Si/ C-IWGN-4-6 cycled in the cut-off range of $0.02-1.5 \mathrm{~V}$. 
(a)
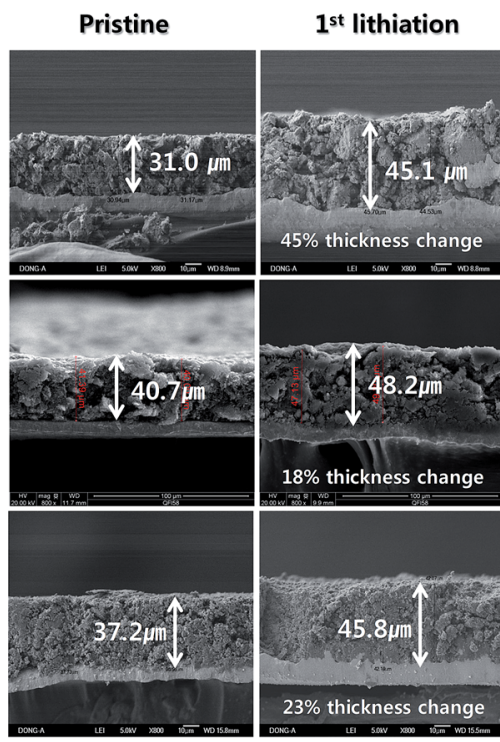

$1^{\text {st }}$ delithiation

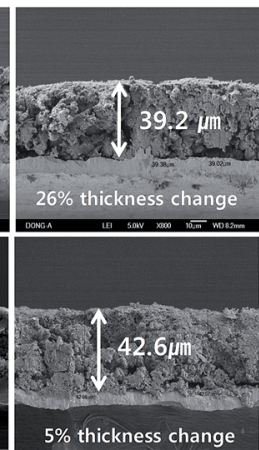

$5 \%$ thickness change

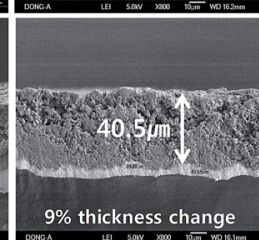

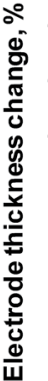

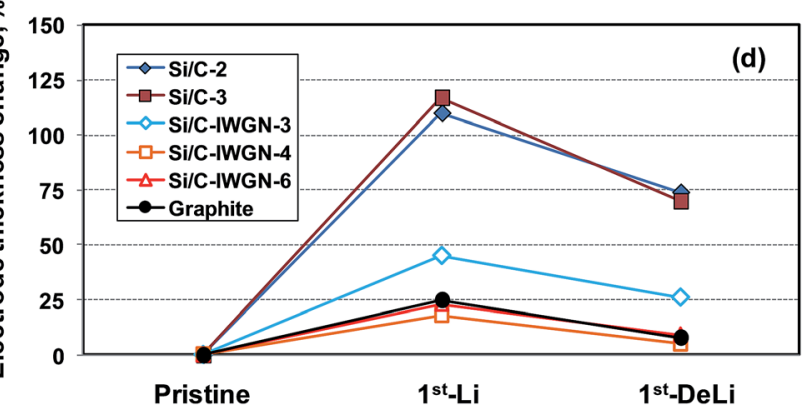

Fig. 10 SEM images of electrode cross-sections of (a) Si/C-IWGN-3, (b) Si/C-IWGN-4 and (c) Si/C-IWGN-6, (d) electrode thickness changes of samples, for their pristine and after the first lithiation and delithiation.

density has to be optimized to achieve the cycling stability and high volumetric capacity at the same time. As shown in Fig. 10, the electrode thicknesses increased by 18 and $5 \%$ over that of the pristine sample, after the first lithiation and de-lithiation of Si/C-IWGN-4, respectively. The corresponding increases in the thickness of Si/C-IWGN-6, which has higher silicon content than Si/C-IWGN-4, were 23 and 9\%, respectively. The changes in the electrode thickness of Si/C-IWGN-4 and Si/C-IWGN-6 are either comparable to or lower than those (25 and $8 \%$, respectively) obtained from a commercial graphite (Fig. 10b and $\mathrm{S} 10 \dagger)$. This indicates that we were able to restrict the increase in the electrode thickness of $\mathrm{Si} / \mathrm{C}$-IWGNs to a level that is comparable to that obtained from commercial graphite because of the void spaces rendered by graphene networks in the composites. However, the electrode resistance has to be further optimized to reduce capacity drop at high currents.

\subsection{Volumetric capacities of Si/C-IWGN composites and graphite}

For alloys such as silicon characterized by a large volume expansion, it is desirable to evaluate their corresponding volumetric capacity and compare it with that of graphite. ${ }^{49}$ As shown in Fig. 11, we have calculated the volumetric capacities of few Si/C-IWGN composites and compared them with that of commercial graphite. For this purpose, the capacities were calculated based on the total amount (weight or volume) of the coated material, which included the active material, the binder, and the conductive additive (see Table S2 $\uparrow$ ). At a current of $100 \mathrm{~mA} \mathrm{~g}^{-1}$, the specific capacities of Si/C-IWGN-3 and Si/CIWGN-6 were 2.7-4.2 times higher than that of graphite. The volumetric capacities of Si/C-IWGN-3 and Si/C-IWGN-6 were 484 and $682 \mathrm{~mA} \mathrm{~h} \mathrm{~cm}{ }^{-3}$, respectively. Thus, these values were either comparable to or 1.4 times higher than that of graphite (483 $\mathrm{mA} \mathrm{h} \mathrm{cm}{ }^{-3}$ ), respectively. The volumetric capacity of graphite was found to be lower than the theoretically estimated value of $818 \mathrm{~mA} \mathrm{~h} \mathrm{~cm}{ }^{-3}\left(=372 \mathrm{~mA} \mathrm{~h} \mathrm{~g}{ }^{-1} \times 2.2 \mathrm{~g} \mathrm{~cm}^{-3}\right){ }^{49,53}$ This is because the total electrode volume included the active material, binder and conductive additive. In summary, we have achieved the remarkable feat of designing Si/C-IWGNs, whose specific capacity is greater than graphite by a factor of up to $2-4$. This novel composite possesses excellent cycling stability, and its volumetric capacity is also much higher than that of graphite.

\subsection{Electrochemical responses of a hybrid, $\mathrm{Si}-\mathrm{Gr}$ sample}

Presently, the commercially available cathode material has a low capacity of about $200 \mathrm{~mA} \mathrm{~h} \mathrm{~g}{ }^{-1,54-56}$ which could be possibly increased to $250-300 \mathrm{~mA} \mathrm{~h} \mathrm{~g}^{-1}$ in the near future. ${ }^{2}$ Therefore, to practically improve the cell energy of LIBs, we need to develop an anode having a capacity of around $\sim 1000 \mathrm{~mA} \mathrm{~h} \mathrm{~g}{ }^{-1} .^{7}$ For this purpose, we need to ideally develop novel silicon-based composites. In particular, a hybrid material consisting of high

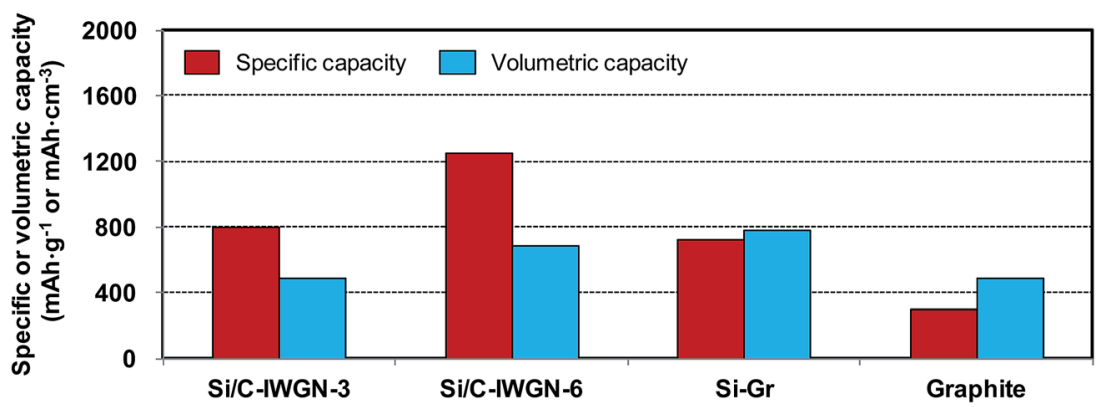

Fig. 11 Comparison of the specific and volumetric capacities of electrodes based on the total electrode weight and volume inclusive of the active material, binder and conductive additive. 

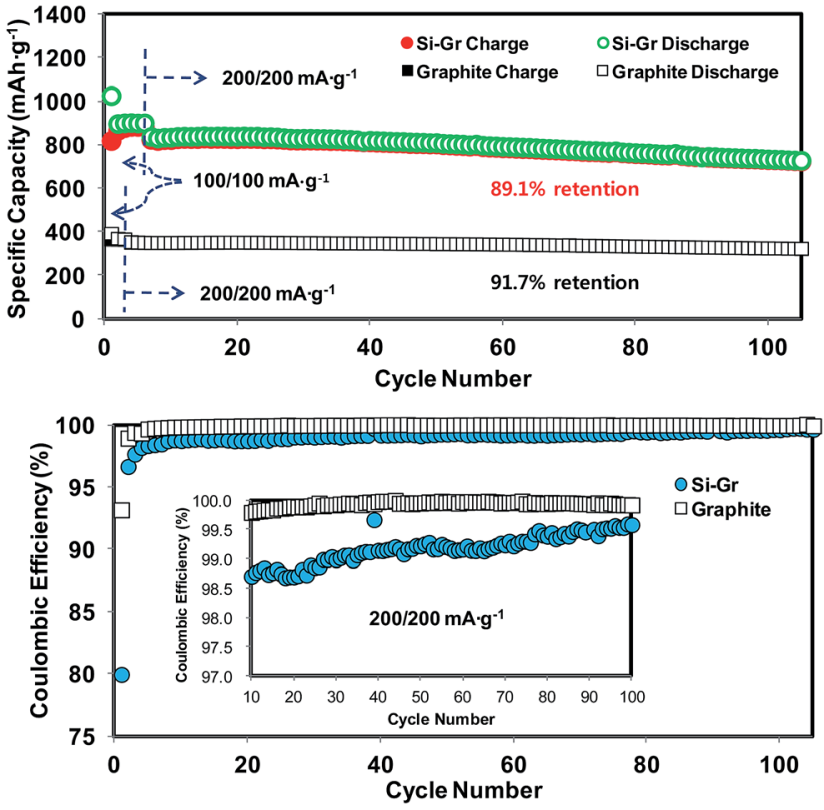

Fig. 12 (a) Cycling performances and (b) coulombic efficiencies of Si$\mathrm{Gr}$ and graphite.

capacity Si-anodes and commercial graphite could be a practical solution for a reliable and cost-effective anode. Therefore, we prepared the Si-Gr hybrid, consisting of Si/C-IWGN-6 (reversible capacity of $1550 \mathrm{~mA} \mathrm{~h} \mathrm{~g}^{-1}$ at $100 \mathrm{~mA} \mathrm{~g}^{-1}$ ) and graphite with a weight ratio of $4: 6$. Then, we evaluated the electrochemical response of this novel hybrid. The expected reversible capacity of the Si-Gr was estimated to be $843 \mathrm{~mA} \mathrm{~h} \mathrm{~g}^{-1}\left(=1550 \mathrm{~mA} \mathrm{~h} \mathrm{~g}^{-1}\right.$ $\left.\times 0.4+372 \mathrm{~mA} \mathrm{~h} \mathrm{~g}^{-1} \times 0.6\right)$. Fig. 12a and b display the cycling performances and CEs of $\mathrm{Si}-\mathrm{Gr}$ and graphite, respectively. The first charge and discharge capacities of the $\mathrm{Si}-\mathrm{Gr}$ hybrid were 1025 and $820 \mathrm{~mA} \mathrm{~h} \mathrm{~g}^{-1}$, respectively, at the first CE of $80.0 \%$. At the currents of 100 and $200 \mathrm{~mA} \mathrm{~g}^{-1}$, the reversible discharge capacities of this hybrid were about 898 and $830 \mathrm{~mA} \mathrm{~h} \mathrm{~g}^{-1}$, respectively. Furthermore, at $200 \mathrm{~mA} \mathrm{~h} \mathrm{~g}^{-1}$, the capacity retention of this hybrid was $89.1 \%$ for 100 cycles. Thus, the capacity retention of this hybrid was close to that of graphite (91.7\%). The CE of Si-Gr increased to $96.6 \%$ in the second cycle and to $99.7 \%$ in the $105^{\text {th }}$ cycle, thereby approaching the CE of graphite. Based on the electrode volume, the volumetric

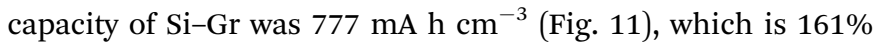
higher than the volumetric capacity obtained from graphite $\left(483 \mathrm{~mA} \mathrm{~h} \mathrm{~cm}^{-3}\right)$. It is even higher than that of Si/C-IWGN-6 (682 $\left.\mathrm{mA} \mathrm{h} \mathrm{cm}{ }^{-3}\right)$ since the coating density of Si-Gr $\left(1.09 \mathrm{~g} \mathrm{~cm}^{-3}\right)$ is greater than that of Si/C-IWGN-6 $\left(0.55 \mathrm{~g} \mathrm{~cm}^{-3}\right)$ (Table S2 $\uparrow$ ). Thus, with this hybridization strategy demonstrated here, we have achieved the performance improvements in volumetric capacity $\left(682 \mathrm{~mA} \mathrm{~h} \mathrm{~cm}^{-3}\right.$ for Si/C-IWGN-6 $\rightarrow 777 \mathrm{~mA} \mathrm{~h} \mathrm{~cm}{ }^{-3}$ for $\mathrm{Si}-\mathrm{Gr}$ ) and CE in the first cycle ( $73 \%$ for Si/C-IWGN-6 $\rightarrow 80 \%$ for $\mathrm{Si} / \mathrm{Gr}$ ). Furthermore, this novel hybrid could be a cost-effective material in comparison with the Si-based composite.

Fig. 13a compares the first and fifth $\mathrm{CV}$ profiles of Si/CIWGN-6, graphite and Si-Gr. The CV profile of Si-Gr seems to be a weight-averaged superposition of the profiles of Si/C-IWGN-6
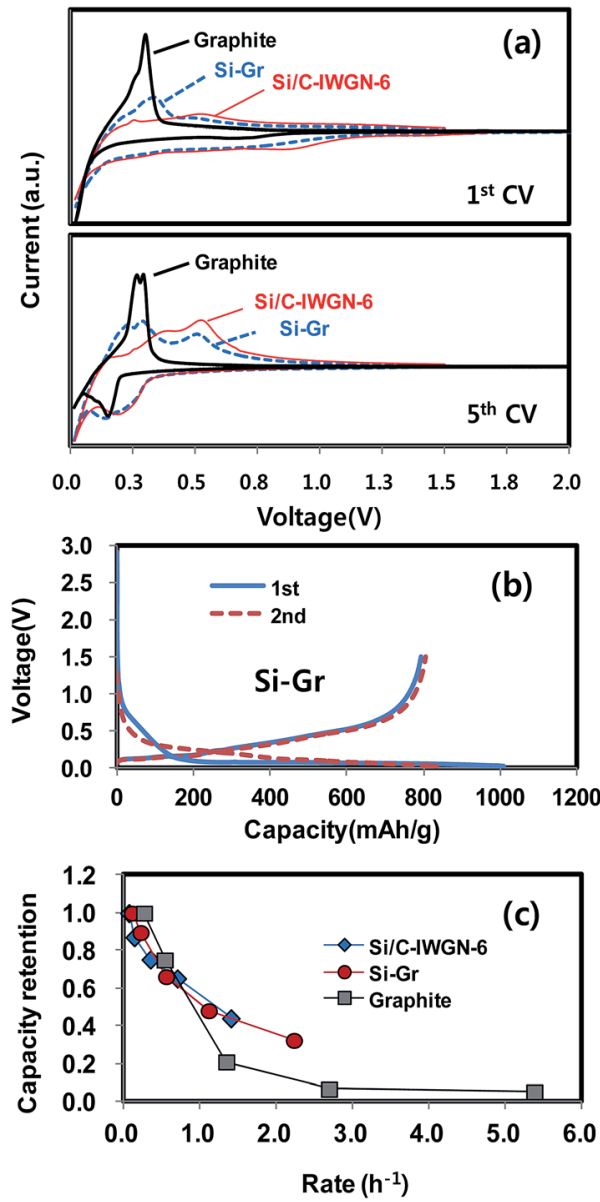

Fig. 13 (a) CV profiles of graphite, Si/C-IWGN-6 and Si-Gr, (b) voltage profiles of Si-Gr and (c) rate responses of graphite, Si/C-IWGN-6 and $\mathrm{Si}-\mathrm{Gr}$.

and graphite. As shown in Fig. 13b, the voltage profile of Si-Gr also reflects the characteristics of those obtained from Si/CIWGN-6 (Fig. 5) and graphite (Fig. S11†). As shown in Fig. 13c, the rate responses of Si/C-IWGN-6, Si-Gr and graphite were obtained by varying the discharge currents in the range of 100$2000 \mathrm{~mA} \mathrm{~g}^{-1}$ at a fixed charge at $100 \mathrm{~mA} \mathrm{~g}^{-1}$. In the C-rate range of 1.1-1.4 $\mathrm{h}^{-1}, \mathrm{Si} / \mathrm{C}-\mathrm{IWGN}-6, \mathrm{Si}-\mathrm{Gr}$ and graphite delivered 624,398 and $78 \mathrm{~mA} \mathrm{~h} \mathrm{~g}^{-1}$. The corresponding capacity retentions were $44.2,48.2$ and $21.0 \%$ of their capacities obtained at $100 \mathrm{~mA} \mathrm{~g}{ }^{-1}$, respectively. This indicates that the alloying/ de-alloying kinetics of silicon are faster than the intercalation/ de-intercalation of graphite.

\section{Conclusions}

In summary, we devised a simple one-pot aqueous sol-gel system to prepare Si/C-IWGN, a novel composite material in which graphene networks were highly dispersed throughout $\mathrm{Si} / \mathrm{C}$ composites; this novel composite was used for high performance LIB anodes. The Si/C-IWGN composites exhibited greater cycling stability compared to reference $\mathrm{Si} / \mathrm{C}$ samples, which consisted of SiNPs that were simply coated with carbon. The characterization and electrochemical responses of this 
novel composite suggest that graphene networks in Si/C-IWGNs not only provide electrical networks but also generate void spaces, which are very effective in absorbing large volume expansions of $\mathrm{Si}$ to the level comparable to that of commercial graphite. Thereby, graphene networks effectively tackled the issue of common electrode pulverization and ensured the cycling stability of Si-based anodes. Compared to commercial graphite, a properly designed Si/C-IWGN composite material exhibited about $\sim 420 \%$ increase in specific capacity and about $\sim 141 \%$ increase in volumetric capacity, which was determined on the basis of electrode weight or volume. We devised a reliable and cost-effective hybrid anode using a mixture of Si/C-IWGN and commercial graphite. $\mathrm{Si}-\mathrm{Gr}$ is a hybrid that offers the capacity level (800-1000 $\mathrm{mA} \mathrm{h} \mathrm{g}^{-1}$ ) required to improve the energy density of current LIB cells. Moreover, the volumetric capacity of the $\mathrm{Si}-\mathrm{Gr}$ electrode is $161 \%$ higher than that obtained from commercial graphite. The $\mathrm{Si}-\mathrm{Gr}$ hybrid also has excellent cycling stability. We conclude that the preparation of $\mathrm{Si} / \mathrm{C}-\mathrm{IWGNs}$ is a scalable process. Moreover, owing to the remarkable electrochemical responses of Si/C-IWGNs, it could be used in manufacturing energy storage devices of high energy density and long cycle life.

\section{Acknowledgements}

This work was supported by grants from the National Research Foundation of Korea funded by the Korean Government (MEST) (NRF-2009-C1AAA001-0093307) and by the Human Resource Training Program for Regional Innovation and Creativity through the Ministry of Education and National Research Foundation of Korea (NRF-2014H1C1A1073093).

\section{References}

1 B. Scrosati and J. Garche, J. Power Sources, 2010, 195, 2419.

2 M. M. Thackeray, C. Wolverton and E. D. Isaacs, Energy Environ. Sci., 2012, 5, 7854.

3 J. Hassoun, K. S. Lee, Y. K. Sun and B. Scrosati, J. Am. Chem. Soc., 2011, 133, 3139.

4 J. M. Tarascon, Philos. Trans. R. Soc., A, 2010, 368, 3227.

5 H. Wu, G. Chan, J. W. Choi, I. Ryu, Y. Yao, M. T. McDowell, S. W. Lee, A. Jackson, Y. Yang, L. B. Hu and Y. Cui, Nat. Nanotechnol., 2012, 7, 309.

6 R. A. Huggins, J. Power Sources, 1999, 82, 13.

7 S. D. Beattie, D. Larcher, M. Morcrette, B. Simon and J. M. Tarascon, J. Electrochem. Soc., 2008, 155, A158.

8 H. Kim, E. J. Lee and Y. K. Sun, Mater. Today, 2014, 17, 285. 9 J. Hassoun and B. Scrosati, Angew. Chem., Int. Ed., 2010, 49, 2371.

10 Y. Yang, M. T. McDowell, A. Jackson, J. J. Cha, S. S. Hong and Y. Cui, Nano Lett., 2012, 10, 1486.

11 R. Elazari, G. Salitra, G. Gershinsky, A. Garsuch, A. Panchenko and D. Aurbach, Electrochem. Commun., 2012, 14, 21.

12 J. Hassoun, J. Kim, D. J. Lee, H. G. Jung, S. M. Lee, Y. K. Sun and B. Scrosati, J. Power Sources, 2012, 202, 308.
13 M. Agostini, J. Hassoun, J. Liu, M. Jeong, H. Nara, T. Momma, T. Osaka, Y. K. Sun and B. Scrosati, ACS Appl. Mater. Interfaces, 2014, 6, 10924.

14 N. S. Choi, K. H. Yew, K. Y. Lee, M. Sung, H. Kim and S. S. Kim, J. Power Sources, 2006, 161, 1254.

15 H. Nakai, T. Kubota, A. Kita and A. Kawashima, J. Electrochem. Soc., 2011, 158, A798.

$16 \mathrm{H}$. Wu, G. Y. Zheng, N. A. Liu, T. J. Carney, Y. Yang and Y. Cui, Nano Lett., 2012, 12, 904.

17 N. Liu, Z. D. Lu, J. Zhao, M. T. McDowell, H. W. Lee, W. T. Zhao and Y. Cui, Nat. Nanotechnol., 2014, 9, 187.

18 B. Philippe, R. Dedryvere, J. Allouche, F. Lindgren, M. Gorgoi, H. Rensmo, D. Gonbeau and K. Edstrom, Chem. Mater., 2012, 24, 1107.

19 N. Liu, H. Wu, M. T. McDowell, Y. Yao, C. M. Wang and Y. Cui, Nano Lett., 2012, 12, 3315.

20 A. Magasinski, P. Dixon, B. Hertzberg, A. Kvit, J. Ayala and G. Yushin, Nat. Mater., 2010, 9, 461.

21 S. R. Chen, M. L. Gordin, R. Yi, G. Howlett, H. Sohn and D. H. Wang, Phys.Chem. Chem. Phys., 2012, 14, 12741.

22 B. Hertzberg, A. Alexeev and G. Yushin, J. Am. Chem. Soc., 2010, 132, 8548.

23 H. Kim, B. Han, J. Choo and J. Cho, Angew. Chem., Int. Ed., 2008, 47, 10151.

24 B. M. Bang, J. I. Lee, H. Kim, J. Cho and S. Park, Adv. Energy Mater., 2012, 2, 878.

25 M. Y. Ge, Y. H. Lu, P. Ercius, J. P. Rong, X. Fang, M. Mecklenburg and C. W. Zhou, Nano Lett., 2014, 14, 261.

26 R. Yi, F. Dai, M. L. Gordin, S. R. Chen and D. H. Wang, Adv. Energy Mater., 2013, 3, 295.

$27 \mathrm{H}$. Wu and Y. Cui, Nano Today, 2012, 7, 414.

28 X. L. Li, M. Gu, S. Y. Hu, R. Kennard, P. F. Yan, X. L. Chen, C. M. Wang, M. J. Sailor, J. G. Zhang and J. Liu, Nat. Commun., 2014, 5, 7.

29 Z. D. Lu, N. Liu, H. W. Lee, J. Zhao, W. Y. Li, Y. Z. Li and Y. Cui, ACS Nano, 2015, 9, 2540.

30 B. Wang, X. L. Li, X. F. Zhang, B. Luo, M. H. Jin, M. H. Liang, S. A. Dayeh, S. T. Picraux and L. J. Zhi, ACS Nano, 2013, 7, 1437.

31 S. M. Paek, E. Yoo and I. Honma, Nano Lett., 2009, 9, 72.

32 J. K. Lee, K. B. Smith, C. M. Hayner and H. H. Kung, Chem. Commun., 2010, 46, 2025.

33 T. Yoon, M. Cho, Y. W. Suh, E. S. Oh and J. K. Lee, J. Nanosci. Nanotechnol., 2011, 11, 10193.

34 X. Zhao, C. M. Hayner, M. C. Kung and H. H. Kung, Adv. Energy Mater., 2011, 1, 1079.

35 K. Evanoff, A. Magasinski, J. B. Yang and G. Yushin, Adv. Energy Mater., 2011, 1, 495.

36 J. Y. Luo, X. Zhao, J. S. Wu, H. D. Jang, H. H. Kung and J. X. Huang, J. Phys. Chem. Lett., 2012, 3, 1824.

37 J.-G. Ren, Q.-H. Wu, G. Hong, W.-J. Zhang, H. Wu, K. Amine, J. Yang and S.-T. Lee, Energy Technol., 2013, 1, 77.

38 C. Chae, H. J. Noh, J. K. Lee, B. Scrosati and Y. K. Sun, Adv. Funct. Mater., 2014, 24, 3036.

39 S. Watcharotone, D. A. Dikin, S. Stankovich, R. Piner, I. Jung, G. H. B. Dommett, G. Evmenenko, S. E. Wu, S. F. Chen, 
C. P. Liu, S. T. Nguyen and R. S. Ruoff, Nano Lett., 2007, 7, 1888.

40 K. S. Novoselov, A. K. Geim, S. V. Morozov, D. Jiang, Y. Zhang, S. V. Dubonos, I. V. Grigorieva and A. A. Firsov, Science, 2004, 306, 666.

41 S. Stankovich, D. A. Dikin, G. H. B. Dommett, K. M. Kohlhaas, E. J. Zimney, E. A. Stach, R. D. Piner, S. T. Nguyen and R. S. Ruoff, Nature, 2006, 442, 282.

42 J. R. Potts, D. R. Dreyer, C. W. Bielawski and R. S. Ruoff, Polymer, 2011, 52, 5.

43 R. Raccichini, A. Varzi, S. Passerini and B. Scrosati, Nat. Mater., 2014, 14, 271.

44 B. Luo and L. Zhi, Energy Environ. Sci., 2015, 8, 456.

45 N. I. Kovtyukhova, P. J. Ollivier, B. R. Martin, T. E. Mallouk, S. A. Chizhik, E. V. Buzaneva and A. D. Gorchinskiy, Chem. Mater., 1999, 11, 771.

46 D. W. S. R. W. Pekala, Macromolecules, 1993, 26, 5487.

47 N. Yan, F. Wang, H. Zhong, Y. Li, Y. Wang, L. Hu and Q. W. Chen, Sci. Rep., 2013, 3, 6.

48 Z. Favors, W. Wang, H. H. Bay, A. George, M. Ozkan and C. S. Ozkan, Sci. Rep., 2014, 4, 7.
49 M. N. Obrovac, L. Christensen, D. B. Le and J. R. Dahnb, J. Electrochem. Soc., 2007, 154, A849.

50 X. Y. Zhou, J. J. Tang, J. Yang, J. Xie and L. L. Ma, Electrochim. Acta, 2013, 87, 663.

51 R. Y. Zhang, Y. J. Du, D. Li, D. K. Shen, J. P. Yang, Z. P. Guo, H. K. Liu, A. A. Elzatahry and D. Y. Zhao, Adv. Mater., 2014, 26, 6749.

52 Z. L. Zhang, Y. H. Wang, W. F. Ren, Q. Q. Tan, Y. F. Chen, H. Li, Z. Y. Zhong and F. B. Su, Angew. Chem., Int. Ed., 2014, 53, 5165.

53 M. Hahn, H. Buqa, P. W. Ruch, D. Goers, M. E. Spahr, J. Ufheil, P. Novak and R. Kotz, Electrochem. Solid-State Lett., 2008, 11, A151.

54 Y. K. Sun, D. H. Kim, C. S. Yoon, S. T. Myung, J. Prakash and K. Amine, Adv. Funct. Mater, , 2010, 20, 485.

55 Y. K. Sun, B. R. Lee, H. J. Noh, H. M. Wu, S. T. Myung and K. Amine, J. Mater. Chem., 2011, 21, 10108.

56 Y. K. Sun, Z. H. Chen, H. J. Noh, D. J. Lee, H. G. Jung, Y. Ren, S. Wang, C. S. Yoon, S. T. Myung and K. Amine, Nat. Mater., 2012, 11, 942. 